\title{
A Biomechanical Study on Single Rod Spinal Instrumentation System in an Unstable Thoracolumbar Injury Model: A Finite Element Analysis
}

\author{
Jereme B. Atupan and Rafael C. Bundoc
}

Section of Spine Surgery, Department of Orthopedics, College of Medicine and Philippine General Hospital, University of the Philippines Manila

\begin{abstract}
Objectives. To develop three dimensional computer models of the anterior thoracolumbar spine implants or constructs (the novel single rod-screw implant and the standard implants) and to evaluate its biomechanical properties through a graphically reconstructed testing standard.

Methods. We developed a finite element modeling technique based on actual geometry of the implant constructs and mechanical property data from standard biomechanical studies on anterior thoracolumbar spinal instrumentation systems. Seven constructs were mounted on simulated vertebral bodies. Axial load sharing was measured through a range of applied axial loads from $100 \mathrm{~N}$ to $1600 \mathrm{~N}$. The static destructive tests were conducted. The bending strength of each construct was calculated with a full length corpectomy graft in place, simulating reconstruction of the anterior column, and with no graft in place, simulating catastrophic graft failure.

Results. Static testing parameter demonstrated highly significant differences between devices. The plate construct formed the highest subset in bending strength of $1000-1100 \mathrm{~N}$, whereas the single rod showed the lowest value of $300-400 \mathrm{~N}$. However, the bending strengths of single rod and dual rod both without bone grafts were not significantly different. With the graft in place, bending strength of the constructs significantly increased beyond the maximum set load of $1600 \mathrm{~N}$, underlying the importance of the graft in overall construct strength.
\end{abstract}

Conclusion. The 3-D finite element models for anterior thoracolumbar instrumentation system were designed with mechanical properties comparable to the actual biomechanical testing results. Although single rod construct has the lowest value, its bending strength is comparable to the standard dual rod system under static axial loading. Bone graft contributed to overall construct stiffness.

Key Words: anterior spinal instrumentation, thoracolumbar spine, biomechanical testing, finite element analysis

Corresponding author: Jereme B. Atupan, MD

Department of Orthopaedics

Philippine General Hospital

University of the Philippines Manila

Taft Avenue, Ermita, Manila, 1000 Philippines

Telephone: +6325548466

Email: jereme_atpn@hotmail.com

\section{Introduction}

Fractures caused by motor vehicular accidents, falls, sports and other recreational activities at the thoracolumbar junction result from an axial loading force acting on a flexed spine. ${ }^{1-6}$ For patients with progressive neurological loss or a major neurological deficit in the setting of substantial canal compromise commonly found in unstable anterior thoracolumbar injuries, 7,8 most investigators have recommended surgery to provide adequate anatomic decompression of the neural elements. This is achieved through vertebral corpectomy and rigid stabilization of the injured segments until biological fusion occurs. ${ }^{9,16}$

Early anterior thoracolumbar instrumentation, developed by Dwyer and Zielke, was used in the correction and stabilization of scoliosis. ${ }^{10,11}$ Unfortunately in the setting of unstable thoracolumbar injuries, the Zielke instrumentation was biomechanically insufficient. ${ }^{12-16}$ This problem has been resolved by the introduction of solid rod system wherein curvature improvement and solid arthrodesis, yet fusion of fewer motion segments are well proven in deformity correction. However, follow-up clinical studies regarding this stability enhanced solid single rod system in the management of unstable thoracolumbar injuries are not available.

Numerous studies have been performed to evaluate the biomechanics of anterior spinal instrumentation using cadaveric or animal tissue and synthetic testing. However, problems of specimen variation, lack of reproducibility, and inability to perform fatigue testing have been pointed out in the previous cadaveric and animal studies while cost of actual expensive spine implants for synthetic testing should also be taken into account.

In the advent of Finite Element Analysis (FEA) computer program, these implants can be reconstructed and subjected to computer simulated stresses where biomechanical properties of such implants can be predicted, compared and analyzed. . $^{17}$ This method of product design and testing is far superior to the manufacturing costs which would accrue if each sample was actually built and tested.

Since operative management entails vast expenses, management would tend to deviate from the standard intervention especially in developing countries where resources and medical insurance system are limited. The Philippine General Hospital being the country's premier 
tertiary hospital strives to fulfill its mission of quality health service, particularly for the underprivileged. But because out-of-pocket payments are the principal means of financing healthcare throughout the country, the majority of indigent patients cannot afford the ideal implant. These patients will develop complications of prolonged bed rest and could result to suboptimal management. If the single rod-2 screw instrumentation system which is considerably affordable, would prove biomechanically comparable to the standard anterior thoracolumbar instrumentation system, or at least provide anterior stabilization in unstable thoracolumbar fractures, then it may be a realistic option in developing countries with limited resources for healthcare. This could be a means to bridge the gap between the underprivileged and quality healthcare.

There are no published reports that specifically compare the characteristics of single rod configuration with the standard anterior thoracolumbar instrumentation system (dual rod system and plate system). The purpose of this study is to develop three-dimensional finite element models of the anterior thoracolumbar spine implants and constructs and examine their load sharing capabilities.

\section{Methods}

A biomechanical study simulating a thoracolumbar corpectomy model was created to compare load sharing capabilities of seven different anterior instrumentation constructs.

This universal mechanical testing machine was developed by Kotani et al. ${ }^{3}$ (Figure 1A) and its geometry and mechanical property were utilized for the reconstruction of the thoracolumbar corpectomy FEA counterpart (Figure 1B).
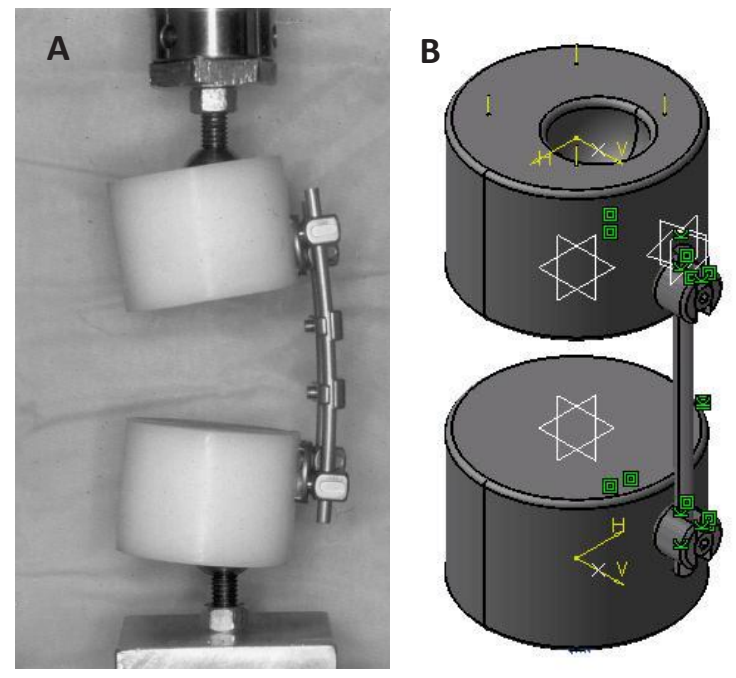

Figure $1 \mathrm{~A}$. Synthetic model and instrumentation assembly as described by Kotani et al. B. 3D synthetic model and instrumentation assembly.

\section{FEA synthetic model and instrumentation assembly}

A computer model of ultra-high-molecular-weight polyethylene (UHMWPE) cylinders (60 $\mathrm{mm}$ in diameter, 42 $\mathrm{mm}$ in height) was developed to represent vertebral elements. The selection of a diameter of $60 \mathrm{~mm}$ was based on the lateral side radius of the third lumbar (L3) vertebral body, allowing the accurate attachment of each device. Two cylinders spanned by spinal instrumentation simulated a total corpectomy defect of $52 \mathrm{~mm}$. The screw location, depth of insertion and the site of compressive lateral bending load application were determined.

\section{FEA implant system or construct}

FEA model of titanium alloy implants were made. Screws were $6.5 \mathrm{~mm}$ in diameter and $35 \mathrm{~mm}$ in length. FEA bone graft was depicted from UHMPE material with $52 \mathrm{~mm}$ height and $25 \mathrm{~mm}$ diameter. These actual physical characteristics (Figure 2) and mechanical properties of implants were applied to develop a 3D coordinate data which was then imported into the CATIA program for 3D modeling and mesh generation.
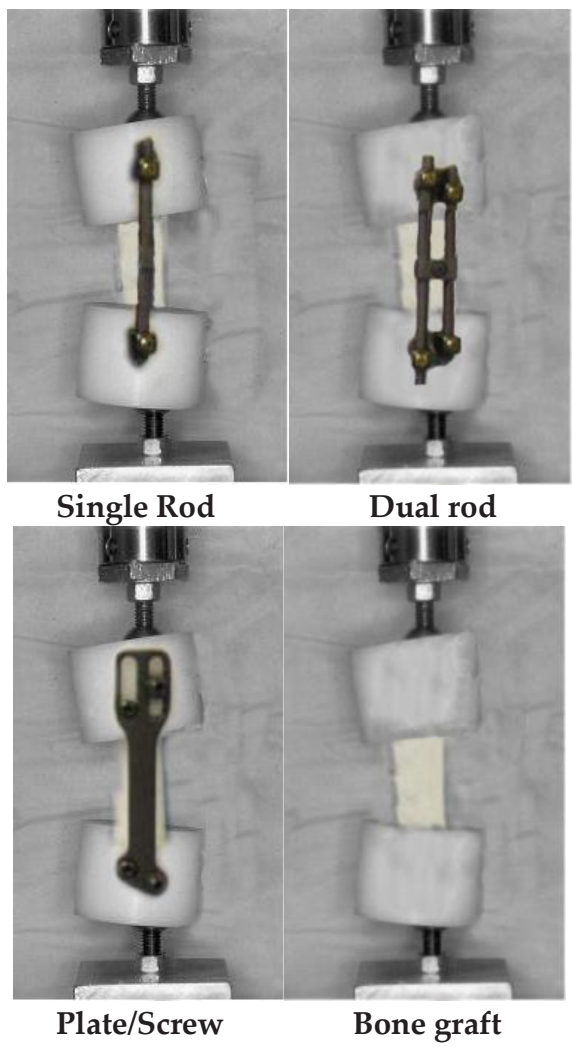

Figure 2. Anterior thoracolumbar implants and the uninstrumented construct ( 3 more constructs with implants but without bone grafts are not shown; total of 7 constructs). The actual dimensions and mechanical properties of the constructs were imported into a surfacer for data processing and subsequently incorporated into the CATIA program for 3D modeling and mesh generation (FEA model). 


\section{Static testing}

The mechanical testing standard and the different constructs for anterior thoracolumbar instrumentation systems were reconstructed and mechanical property analyses were performed using the FEA program (Figure 3).
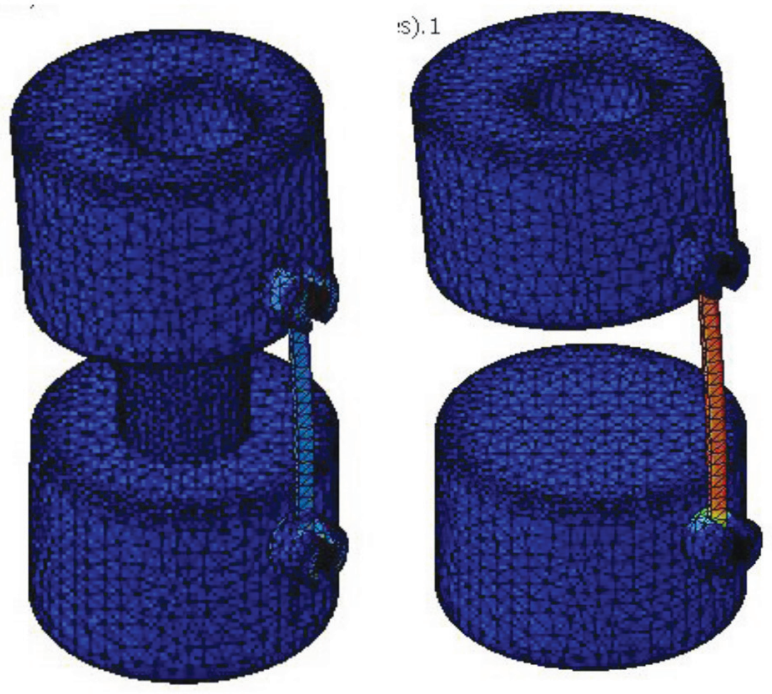

Figure 3. Single rod - FEA model with and without bone graft for static testing.

Ten FEA samples for each seven anterior thoracolumbar construct were tested in static mode: (1) standard spinal plate- 4 screw system with and without synthetic bone graft, (2) standard dual rod-4 screw system with and without synthetic bone graft, (3) Index single rod-2 screw system with and without synthetic bone graft, and the (4) uninstrumented construct (spinal corpectomy model with synthetic bone graft alone).

The static test included axial compressive loading. Each construct was mechanically tested with bending loads of $100 \mathrm{~N}$ to $1600 \mathrm{~N}$ using computer simulation. Bending strength or failure was based on the maximum stresses recorded within the constraints of the construct and the estimated or computed design factor for safety.

\section{Statistical analysis}

Descriptive measures and Kruskal-Wallis nonparametric test were employed to compare the bending strength of the seven instrumentation systems. Analysis of variance was utilized to determine the difference of the bending strength between constructs. The test was significant if the $p$-value is $\leq 0.05$. T-test and Mann-Whitney $\mathrm{U}$ test were employed for the pair-wise mean or median comparison of the normal and non-normal data sets, respectively. The test was significant if the $p$-value is $\leq 0.05$. The data were analyzed using STATA Version 10.

\section{Results}

Static testing through FEA demonstrated significant differences among the devices. The bending strength of the constructs without the bone graft ranged from $300 \mathrm{~N}$ (Single Rod construct) to 1100 N (Plate construct). The dual rod construct had a bending strength mid range value of 400-500 N (Table 1 and Figure 4).

Table 1. Descriptive Statistics between Instrumentation in Static Testing Parameter

\begin{tabular}{llcc}
\hline \multicolumn{1}{c}{ Construct } & $\begin{array}{c}\text { Yield } \\
\text { strength } \\
\mathbf{( N / m 2 )}\end{array}$ & $\begin{array}{c}\text { Bending } \\
\text { strength in } \\
\text { Newton (N) }\end{array}$ & $\begin{array}{c}\text { Descriptive } \\
\text { measure } \\
\text { (Mean) }\end{array}$ \\
\hline Single Rod w/o BG & $1.65-1.23^{* *}$ & $300-400$ & $1.34 \pm 1.44$ \\
Dual Rod w/o BG & $1.72-1.22^{* *}$ & $400-500$ & $1.91 \pm 2.08$ \\
Plate and Screw w/o BG & $1.52-1.27^{* *}$ & $1000-1100$ & $4.09 \pm 4.43$ \\
No Implant w/ BG & $>5-7^{*}$ & $>1600$ & NA \\
Plate and Screw w/ BG & $>5-7^{*}$ & $>1600$ & NA \\
Dual Rod w/ BG & $>5-7^{*}$ & $>1600$ & NA \\
Single Rod w/ BG & $>5-7^{*}$ & $>1600$ & NA \\
\hline
\end{tabular}

**1.5: Design factor for minimum loading

*5-7: Design factor for moderate to maximum shock loading

NA: Not applicable or not measured

BG: Bone graft

The performance of the plate construct within static loading conditions was statistically significant $(\mathrm{P}<0.05)$ compared to the dual rod and the single rod constructs. The bending strengths between single rod and dual rod configurations (both without bone grafts) however were not

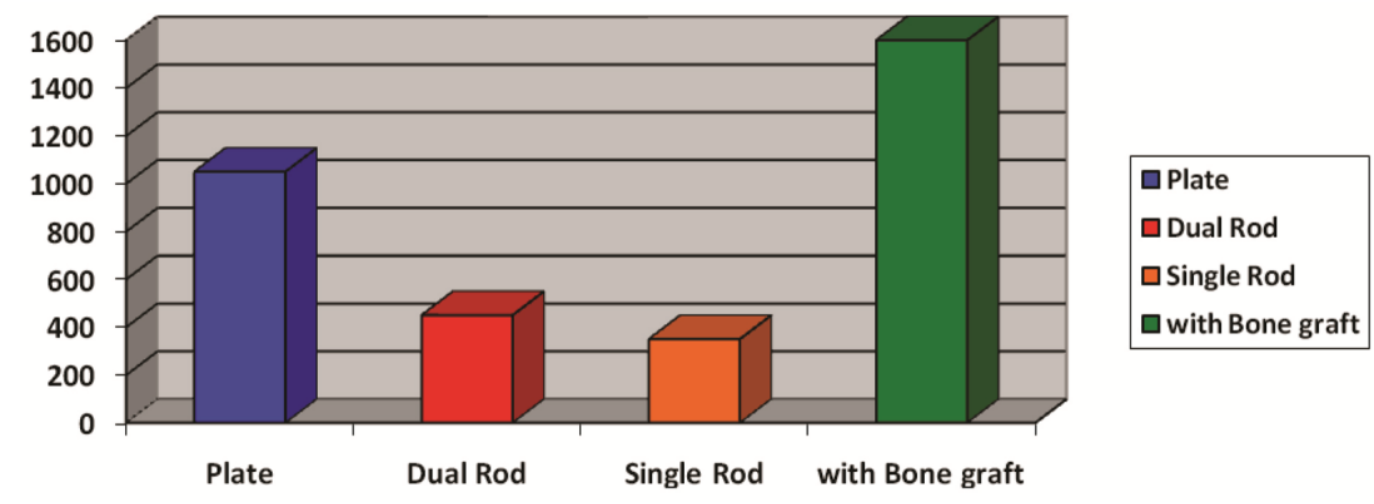

Figure 4. Bending strengths of FEA models in Newton (N) 
significantly different (Tables 2 and 3). On the other hand, with the bone grafts in place during compressive loading, all devices had improvement of stiffness with bending strengths more than the maximum set load of $1600 \mathrm{~N}$.

\section{Discussion}

Vertebral body corpectomies in the thoracic and lumbar spine segments are commonly performed in the treatment of traumatic, malignant, and infectious disorders of the spine.1,2,3,4 Following a partial or complete removal of a vertebral body, the anterior column is commonly reconstructed with bone graft, reconstruction cages, or both. ${ }^{11}$ After the provisional reconstruction of the anterior column, the affected motion segment is considered unstable until bony union between the vertebral bodies above and below the corpectomy defect occurs. This construct is then reinforced with a screw/dual rod system or a screw/plate system. Placement of screw/dual-rod systems such as the Kaneda device with cross-links is effectively similar to screw/plate system. ${ }^{1,2}$ Internal fixation of the spine in this setting is intended to permit the patient to be mobilized while simultaneously creating an adequate environment for bony healing.

Table 2. Comparison of Pair-Wise Mean and Median Values between Instrumentation

\begin{tabular}{llc}
\hline INSTRUMENTATION & \multicolumn{1}{c}{ COMPARED TO } & p-value \\
\hline Single Rod w/o BG (1) & Dual Rod w/o BG ( *ns) & 0.3941 \\
& Plate and Screw w/o BG & 0.0135 \\
& No Implant w/ BG & 0.0000 \\
& Plate and Screw w/ BG & 0.0000 \\
& Dual Rod w/ BG & 0.0002 \\
& Single Rod w/ BG & 0.0002 \\
Dual Rod w/o BG (2) & Plate and Screw w/o BG ( ${ }^{*}$ ns) & 0.0785 \\
& No Implant w/ BG & 0.0000 \\
& Plate and Screw w/ BG & 0.0000 \\
& Dual Rod w/ BG & 0.0002 \\
Plate and Screw w/o BG (3) & Single Rod w/ BG & 0.0002 \\
& No Implant w/ BG & 0.0000 \\
& Plate and Screw w/ BG & 0.0000 \\
& Dual Rod w/ BG & 0.0002 \\
No Implant w/ BG (4) & Single Rod w/ BG & 0.0002 \\
& Plate and Screw w/ BG & 0.0010 \\
& Dual Rod w/ BG & 0.0002 \\
Plate and Screw w/ BG (5) & Single Rod w/ BG & 0.0002 \\
Dual Rod w/ BG (6) & Dual Rod w/ BG & 0.0022 \\
\hline * Not significant & Single Rod w/ BG ( *ns) & 0.1988 \\
& Single Rod w/ BG (7) & 0.0156 \\
\hline
\end{tabular}

The use of anterior instrumentation may increase the stability and fusion rate of corpectomy reconstructions, alter the postoperative bracing requirements, limit the surgery to a single approach, and save motion segments by avoiding larger posterior fusions. ${ }^{1,2,3,11,19}$ As anterior spinal instrumentation has rapidly evolved in recent years, numerous bench-top biomechanical studies have been performed. ${ }^{1,3}$ However, literature regarding anterior thoracolumbar stabilization using the single rod style is scarce.

Table 3. Multiple Comparison Among Spinal Constructs In Bending Strength (NEWTON - N)

\begin{tabular}{|c|c|c|c|c|}
\hline & $\begin{array}{c}\text { Single } \\
\text { rod with } \\
\text { bone } \\
\text { graft }\end{array}$ & $\begin{array}{c}\text { Dual rod } \\
\text { with } \\
\text { bone } \\
\text { graft } \\
\end{array}$ & $\begin{array}{c}\text { Plate/ } \\
\text { screw with } \\
\text { bone graft }\end{array}$ & $\begin{array}{c}\text { Un- } \\
\text { instrumented/ } \\
\text { bone graft } \\
\text { alone }\end{array}$ \\
\hline $\begin{array}{l}\text { Single rod with } \\
\text { bone graft }\end{array}$ & & No & Yes & Yes \\
\hline $\begin{array}{l}\text { Dual rod with } \\
\text { bone graft }\end{array}$ & No & & Yes & Yes \\
\hline $\begin{array}{l}\text { Plate/screw with } \\
\text { bone graft }\end{array}$ & Yes & Yes & & Yes \\
\hline $\begin{array}{l}\text { Un-instrumented/ } \\
\text { bone graft alone }\end{array}$ & Yes & Yes & Yes & \\
\hline
\end{tabular}

The current study has reconstructed 3-D finite element models of the anterior thoracolumbar instrumentation and the standard testing model. These parameters were based on the synthetic model for biomechanical testing described by Brodke et al. ${ }^{2}$ and Kotani et al. ${ }^{3}$ with large array of instrumentation systems tested.

The current study demonstrated that bending strengths of the 3-D FEA models are similar to the bending strength of the actual instrumentation systems tested in vitro (Figure 5). Our dual rod version was comparable to the actual dual rod system, the Kaneda device. The FEA plate construct model on the other hand was similar to the University plate as far as bending strength is concern. Brodke et al. ${ }^{2}$ and Kotani et al. ${ }^{3}$ showed in their studies that there were no substantial differences in stiffness between rod devices and plate devices. The implant type therefore does not influence the biomechanical property of the construct. Although they were statistically different in the current study, the 3-D models of the plate and dual rod construct were patterned from the superior quality plate counterpart and the inferior quality dual rod counterpart, the USA plate and Kaneda device, respectively. Thus it showed statistical difference between the constructs.

The novel single rod FEA model although having the lowest bending strength value of $300-400 \mathrm{~N}$, was statistically equivalent to the dual rod FEA model. Because of this inference, it implies that single rod model is comparable to the actual Z-plate and Kaneda device under Static axial loading condition. The bending strengths of the Z-plate and Kaneda device are $407 \mathrm{~N}$ and $565 \mathrm{~N}$, respectively (Figure 5). ${ }^{2}$ These bending strengths are similar and compatible with the compressive load acting on the upper lumbar vertebrae of a $70 \mathrm{~kg}$ man in a standing position. ${ }^{20}$

Finally, the bending strengths of all constructs with bone graft were not measured. However, the current study was able to demonstrate that adding an inter-positional bone graft would greatly increased the strength of the 


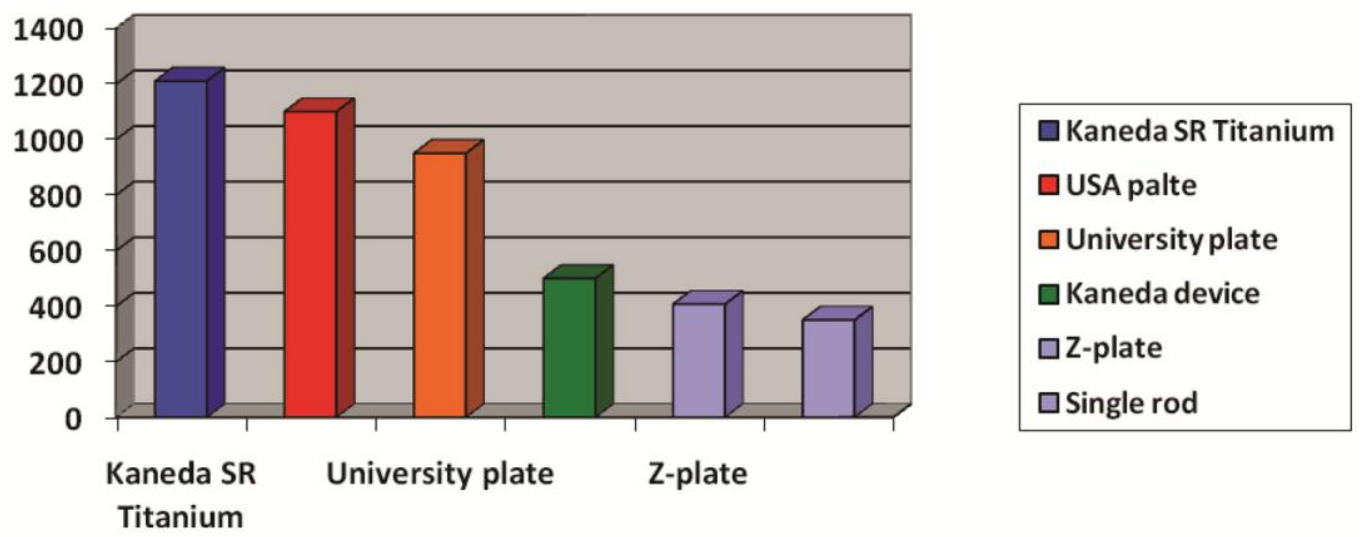

Figure 5. Bending strengths of standard implants versus FEA single rod model

construct. The constructs with bone graft remained intact even on $1600 \mathrm{~N}$ static axial loading. $1600 \mathrm{~N}$ was chosen based on the optimum physiologic loading of the thoracolumbar spine. The presence of the graft contributed to the overall construct stiffness in all instrumentation systems. This underlines the importance of the graft in the overall construct stiffness.

\section{Conclusion}

Having a realistic mathematical model of the spine and instrumentation system would further establish itself as a useful adjunct to the experimental approaches for investigating clinical problems of the spine and may be used to predict biomechanical responses of the spine under physiological and trauma loadings.

The anterior thoracolumbar instrumentation systems were designed via 3D finite element modeling technique. The mechanical properties for each computer model were similar to the instrumentation systems or constructs tested in vitro. It provided a repeatable and consistent experimental condition controlling dimensional and surgical factors. Although the single rod construct has the lowest value, its bending strength is comparable to the standard dual Rod system. It can therefore resist physiologic burden under axial static loading conditions. The comparison of instrumentation systems highlights the importance of mechanically balanced device design without a weak link in the development of instrumentation. In this case, the interpositional bone graft, which contributed to overall construct stiffness.

\section{Limitations of the study and recommendations}

There are several limitations in this study. FEA mechanical analysis was based on synthetic testing. The UHMWPE-screw interface is stronger than the bone-screw interface, and construct stiffness of the instrumentation mounted to human bone would most likely be less than what will be measured in this study. This will show some contrast to clinical outcome results. We therefore recommend that a follow-up study be performed with implants mounted on human lumbar vertebrae models to closely approximate human cadaveric studies.

The study only analyzed static or bending strength. Other stresses present in the normal load patterns of the thoracolumbar segment like shear and rotation stresses as well as fatigue testing is recommended in the analysis.

\section{Acknowledgments}

The authors wish to thank DeLa Salle University-Manila, Department of Manufacturing Engineering and Management for providing the FEA computer program.

\section{References}

1. Hitchon PW, Goel VK, Rogge T, Grosland NM, Torner J. Biomechanical studies on two anterior thoracolumbar implants in cadaveric spines. Spine. 1999;24(3):213-8.

2. Brodke DS, Gollogly S, Bachus KN, Alexander Mohr R, Nguyen BK. Anterior thoracolumbar instrumentation: stiffness and load sharing characteristics of plate and rod systems. Spine. 2003;28(16):1794-801.

3. Kotani Y, Cunningham BW, Parker LM, Kanayama M, McAfee PC. Static and fatigue biomechanical properties of anterior thoracolumbar instrumentation systems. A synthetic testing model. Spine. 1999;24(14):1406-13.

4. Kostuik JP. Anterior fixation for fractures of the thoracic and lumbar spine with or without neurologic involvement. Clin Orthop Relat Res. 1984;(189):103-15.

5. Wood K, Buttermann G, Mehbod A, Garvey T, Jhanjee R, Sechriest V. Operative compared with nonoperative treatment of a thoracolumbar burst fracture without neurological deficit: A prospective, randomized study. J Bone Joint Surg Am. 2003;85-A(5):773-81.

6. Knight RQ, Stornelli DP, Chan DP, Devanny JR, Jackson KV. Comparison of operative versus nonoperative treatment of lumbar burst fractures. Clin Orthop Relat Res. 1993;(293):112-21.

7. Shen WJ, Liu TJ, Shen YS. Nonoperative treatment versus posterior fixation for thoracolumbar junction burst fractures without neurologic deficit. Spine. 2001;26(9):1038-45.

8. Shen WJ, Shen YS. Nonsurgical treatment of three-column thoracolumbar junction burst fractures without neurologic deficit. Spine. 1999;24(4):412-5. 
9. Sobel JW, Bohlman HH, Freehafer AA. Charcot's arthropathy of the spine following spinal cord injury. A report of 5 cases. J Bone Joint Surg Am. 1985;67(5):771-6.

10. Thalgott J, LaRocca H, Gardner V, et al. Reconstruction of failed lumbar surgery with narrow AO DCP plates for spinal arthrodesis. Spine. 1991;16(3 Suppl):S170-5.

11. Baron E, Zeiller S, Vaccaro A, Hilibrand A. Surgical Management of Thoracolumbar Fractures. Contemporay Spine Surgery. 2006;7(1):1-7.

12. Sasso RC, Best NM, Reilly TM, McGuire RA Jr. Anterior-only stabilization of three-column thoracolumbar injuries. J Spinal Disord Tech. 2005;18(suppl):S7-14.

13. Zdeblick TA, Shirado O, McAfee PC, deGroot H, Warden KE. Anterior spinal fixation after lumbar corpectomy. A study in dogs. J Bone Joint Surg Am. 1991;73(4):527-34.

14. Been HD. Anterior decompression and stabilization of thoracolumbar burst fractures by the use of the Slot-Zielke device. Spine. 1991;16(1):707.

15. Zdeblick TA, Warden KE, Zou D, McAfee PC, Abitbol JJ. Anterior spinal fixators: a biomechanical in vitro study. Spine. 1993;18(4):513-7.

16. Vaccaro A, Kim D, Brodke D, et al. Diagnosis and management of thoracolumbar spine fractures. J Bone Joint Surg Am. 2003;85(12):245670 .

17. Baran NM. Finite element analysis on microcomputers. New York: McGraw-Hill Book Company; 1988.

18. Irons B, Shrive N. Finite element primer. John Wiley \& Sons, Inc.; 1983.

19. Dunn HK. Anterior stabilization of thoracolumbar injuries. Clin Orthop Relat Res. 1984;(189):116-24.

20. Liebschner MA, Kopperdahl DL, Rosenberg WS, Keaveny TM. Finite element modeling of the human thoracolumbar spine. Spine. 2003;28(6):559-65.

\section{OPERATIONAL DEFINITION OF TERMS}

Anterior column - anterior two thirds of vertebral body, anterior part of annulus fibrosus and anterior longitudinal ligament.

Axial loading - a force with its resultant vector passing thru the centric of the particular section and being perpendicular to the plane of section. Or force passing thru the longitudinal axis.

Bending strength - the ability of a structural member to resist breakage when subject to one or more external forces that cause it to bend.

Finite Element Analysis - consists of a computer model of a material or design that is stressed and analyzed for specific results. It is used to predict the life of a material or structure by showing the effects of cyclic loading on the specimen exemplified by fatigue analysis. It can be used in predicting failure due to unknown stresses by showing problem areas in a material and allowing designers to see all of the theoretical stresses within.

Three column injury - instability or disruption of the anterior, middle and posterior columns of the vertebra.

Unstable anterior Thoraco-lumbar fracture - instability or disruption of the anterior and middle column elements of the thoracolumbar segment with intact posterior column.

Vertebral corpectomy - partial or complete removal of the vertebral body.

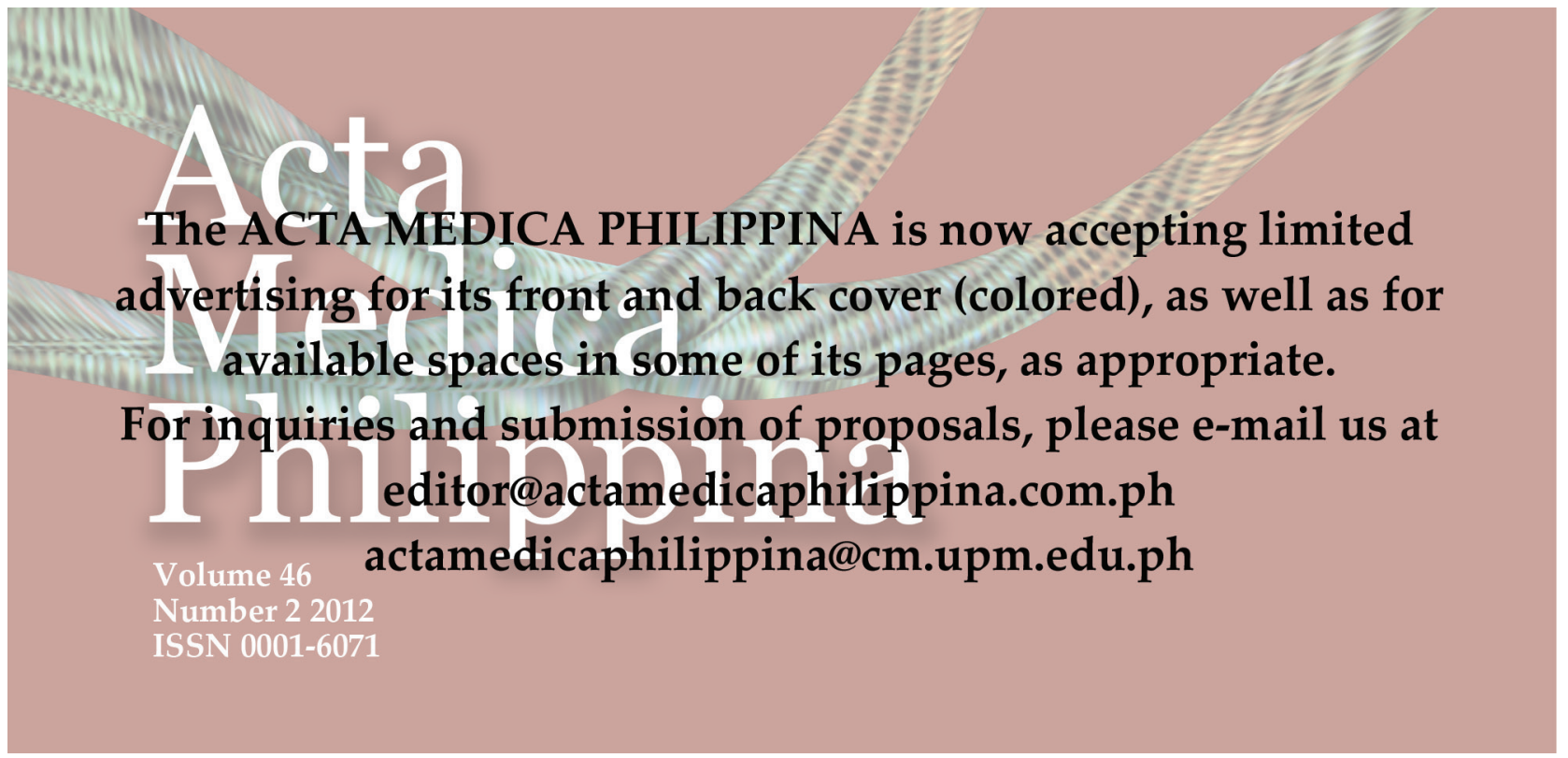

